\begin{tabular}{|c|c|}
\hline Citation & $\begin{array}{l}\text { Kim Loyens, Jeroen Maesschalck; (2014) } \\
\text { Police-public interactions: A grid-group cultural theory perspective } \\
\text { Policing: An International Journal of Police Strategies \& Management, 37(1), } \\
\text { 144-158. }\end{array}$ \\
\hline Archived version & $\begin{array}{l}\text { Author manuscript: the content is identical to the content of the published } \\
\text { paper, but without the final typesetting by the publisher }\end{array}$ \\
\hline Published version & http://dx.doi.org/10.1108/PIJPSM-03-2013-0023 \\
\hline Journal homepage & http://www.emeraldinsight.com/journal/pijpsm \\
\hline Author affiliation & $\begin{array}{l}\text { Kim Loyens, Leuven Instititute of Criminology, Faculty of Law, KU Leuven } \\
\text { (University of Leuven), Belgium } \\
\text { Jeroen Maesschalck, Leuven Instititute of Criminology, Faculty of Law, KU } \\
\text { Leuven (University of Leuven), Belgium }\end{array}$ \\
\hline Author contact & $\begin{array}{l}\text { kim.loyens@law.kuleuven.be , jeroen.maesschalck@law.kuleuven.be } \\
+32 \text { (0) } 16329452,+32 \text { (0) } 16325558\end{array}$ \\
\hline IR & http://lirias.kuleuven.be/handle/123456789/403754 \\
\hline
\end{tabular}

(article begins on next page) 


\title{
Police-public interactions: \\ A grid-group cultural theory perspective
}

\begin{abstract}
Purpose - The police culture literature suggests that police officers' attitude towards the public is characterised by suspicion and an "us-vs-them" mentality. It also refers to the moral mission of protecting the public by being tough on crime. The traditional police culture model seems to imply that these aspects are typical for the police. There is, however, a lack of empirical studies to test this proposition. The purpose of this paper is to propose a different conceptual framework, based on grid-group cultural theory (GGCT), which not only broadens the lens of the police culture model, but also allows for comparative research between different professional groups.

Design/methodology/approach - The newly developed conceptual framework is tested in an ethnographic study in the Belgian police and labour inspection. The main data collection methods are observation, interview and informal conversation.

Findings - The results of this study show that there are similarities in the way in which Belgian police officers and labour inspectors interact with the public, which raises interesting questions concerning the (often implicit) claim of the police culture literature concerning the specificity of police culture.

Research limitations/implications - More research is needed to gain deeper insight into similarities and differences of the occupational culture in the police and comparable professional groups. GGCT offers a useful conceptual framework for such a research agenda.

Originality/value - This paper addresses a number of criticisms against the classic police culture model and provides an innovative perspective to not only study aspects of police culture, but also compare the police with other professions.
\end{abstract}




\section{Introduction}

Since the innovative ethnographic research in the 1960s and 1970s, the traditional police culture model has assumed the existence of a specific set of cultural characteristics that are thought to be typical for the police across time and space. This model has also been strongly criticized. Recent studies on police culture therefore have attempted to bring the traditional literature up to date by focusing on the impact of societal developments and organisational reforms on the contemporary police culture (e.g. Chan, 1996; Herbert, 1998; McLaughlin, 2007; Loftus, 2009). However, most of these studies do not address the fundamental question whether the occupational culture in police agencies is typical for the police or, on the contrary, shows similarities with the occupational culture in other, comparable professions (e.g. private security, labour inspection).

An important aspect in the police culture literature is the attitude towards the public. Concepts like 'moral cynicism', 'social isolation' and 'crime fighter image' give a rather negative connotation to the way in which police officers perceive the public. There is, however, virtually no research on the differences and similarities between the police's and other professional groups' patterns of interaction with the public. This probably results from the fact that the concepts used in the police culture literature are profession-specific. This paper proposes an alternative conceptual framework to study these aspects of police culture by using the more profession-neutral grid-group cultural theory (GGCT), thus enabling comparative research in different professional groups. This paper starts with a general overview of the way in which the classic police culture literature presents police-public interactions. Then, two important criticisms will be discussed that have been raised against it. These criticisms are addressed by using GGCT as an alternative framework. This newly developed framework will then be applied in a Belgian ethnographic study in which the police are compared with the labour inspection. This paper aims to illustrate how GGCT can capture other concepts and themes that have not yet been dealt with in the traditional police culture literature, thus broadening the latter's analytic lens.

\section{Interaction with the public in the police culture literature}

The classic police culture literature presents police-public interactions in a rather negative way. It states that police officers look at the public with suspicion. This is mostly explained by their frequent encounters with lawbreakers or the 'dark side' of society. It is assumed that most citizens police officers are confronted with are felons. The police job is therefore often referred to as being 'dirty work' in 'a jungle' where crime, corruption and brutality are normal aspects of everyday reality (e.g. Westley, 1970; McLaughlin, 2007). In addition, police officers should constantly be aware of potential threats to their safety (Van Maanen, 1974; Skolnick, 1975; Brown, 1981; Crank, 1997). Researchers in the police culture tradition claim that this suspicion and caution lead to social isolation. Police officers, it is said, consider themselves to be part of a specific social and occupational group of the 'good guys' fighting the 'bad guys', by which they isolate themselves from the general public. In other words, they develop an 'us-versus-them' attitude (Westley, 1970; Paoline, 2003). The 'fighting the bad guys' idea could, however, lead to a misguided pursuit of 'noble cause', trying to achieve valuable ends by unlawful or inappropriate means (Reiner, 1992). Police officers then believe they 
are allowed to disregard legal procedures if these seem to be ineffective to catch the 'bad guys' (Reiner, 1992).

While the attitude of suspicion is mostly oriented towards lawbreakers, the police culture literature states that towards other citizens - particularly victims of crime - police officers have a powerful sense of mission. They want to protect the public from crime (Crank, 1997). This is reflected in police officers' self-perception of being 'the thin blue line', which means that they consider crime fighting and safeguarding social order central aspects of their work (Chan, 1996). This sense of mission implies, according to the police culture literature, that police officers consider strategies like community-oriented policing as too 'soft' and hence not 'real' police work (Terrill, Paoline, \& Manning, 2003). They are cops and not social workers; they should, participate in the 'war against crime' (Reiner, 1992).

The police are also said to be vulnerable to moral cynicism. Authors in the police culture literature explain this in a twofold way. First, the moral mission is often difficult to achieve in practice, because there is a discrepancy between what police officers aim to do and what they realistically can accomplish (van Buuren \& den Boer, 2008). Second, moral cynicism can result from the frequent encounters with lawbreakers. Goldstein, describes it as follows:

The average officer - especially in large cities - sees the worst side of humanity. He is exposed to a steady diet of wrongdoing. He becomes intimately familiar with the ways people prey on one another. In the course of this intensive exposure he discovers that dishonesty and corruption are not restricted to those the community sees as criminal. He sees many individuals of good reputation engaging in practices equally dishonest and corrupt [...]. It is not unusual for him to develop a cynical attitude in which he views corruption as a game in which every person is out to get his share. (Goldstein, 1975: 25)

\section{Criticisms against the traditional police culture model}

The traditional police culture literature did not remain uncriticized. Various objections have been raised against it. Two of them will be discussed below, identifying not only the weaknesses of the classic police culture literature, but also some recent attempts at improvement.

\section{A normative approach with a negative connotation}

Traditionally, the police culture literature gives a rather negative connotation to its core concept (Prenzler, 1997). Applied to the interaction with the public (the topic of this paper), this can be illustrated with concepts like 'social isolation', 'moral cynicism' and 'noble cause corruption', but also by referring to the presumed unwillingness of the police to perform community-oriented policing tasks. This pejorative connotation implies the risk of blindness to other, more positive aspects of police culture. There is, however, a particular line of research with a focus on these positive aspects (e.g. Manning, 1995; Paoline, 2003). It has been acknowledged that some aspects of police occupational culture that seem only to have negative consequences can be highly functional in some situations. A case in point is moral cynicism as the 'Janus face of commitment' (Reiner, 1992). This means that police officers need some degree of cynical acquiescence to be able to cope with the 
heavy load of the 'crime fighter' imperative on their shoulders. In addition, Crank (1998) explains that, although in social life obvious displays of distrust are not appreciated, suspicion is an important skill in policing, because it enables officers to identify wrongdoers on the basis of only a few indications.

Hence, there are conflicting statements about police-public encounters if you compare the classic police culture literature with more recent versions of this literature. Arguably, this suggests complexity rather than contradiction. In this, we agree with Harrison (1998) who claims that "the discussion of culture tends to be cast in the light of its potential negative effects". He observes that "Ili]ttle has been written about the possible beneficial effects of these same cultural characteristics on the organisation". The application of a more neutral organisational culture model could, at least partly, solve this problem.

\section{Lack of cultural variation}

The second and most important criticism on the traditional police culture literature relates to the overall lack of variation. The classic literature does not allow for much variation in terms of region nor scope. This twofold lack of variation will be discussed below, as well as ways in which some researchers have tried to overcome this problem.

First, the police culture model and its central concepts have predominantly been developed on the basis of empirical research in English-speaking countries. The number of internationally published studies in other parts of the world is limited. Studies have, for example, been conducted in the Netherlands (Punch, 1979), France (Monjardet, 1994), Japan (Ames, 1981; Bayley, 1991), China (Jiao, 2001), and South Africa (Brogden \& Shearing, 1993). Despite parallels, there are indications of a number of essential differences in the mission of police organisations, the education of individual officers, stringency of regulation, and the dangerousness of the police job (Skolnick, 1975; Monjardet, 1994; Harrison, 1998). These differences, in turn, might have an impact on the interaction between police officers and the public. Hence, the way in which the traditional literature presents this interaction could lack relevance in non-Anglo-Saxon countries, which again illustrates the need for a more neutral organisational culture approach.

The second aspect of narrowness in the police culture literature concerns the lack of variation in scope. Two examples can illustrate this. First, the police culture literature is mainly based on studies of policing 'on the beat' (McLaughlin, 2007). This implies the risk that the findings are not relevant for other aspects of the police job, such as the investigative work of detectives. Second, there is also a lack of theoretical development in police culture studies. Despite a few conceptual adjustments in recent decades, most recent studies still focus on themes and concepts that have been addressed in the classic studies. They conclude that the 'crime fighter image' and social isolation have, at least partly, been abandoned (Mastrofski, Worden, \& Snipes, 1995; McLaughlin, 2007; Loftus, 2009). However, research that starts from the classic concepts and mainly refers to the absence or reduction of these traditional aspects seems to overlook other developments in police culture that are not captured by the traditional model. In other words, although concepts like the 'crime fighter' 
image and 'social isolation' still bear some relevance, continuing to include them as central concepts in the model implies the risk of hindering researchers from looking beyond these traditional aspects. Nevertheless, some researchers do expand the theoretical scope of the police culture model by also adding the impact of broader societal and organisational factors. Herbert (1998) developed the concept of 'normative order' referring to a set of rules and practices related to a central value. Drawing on broader developments in the sociology of culture, he perceives culture as a 'tool kit' filled with stories, rituals and world views that staff members in organisations use to determine how they can respond to both uncertain and routine situations (Swidler, 1986). He distinguished between six normative orders in police organisations (i.e. law, bureaucratic control, adventure/machismo, safety, competence and morality) that are in constant conflict due to a lack of internal consistency. This classification allows for understanding differences between police departments (Herbert, 1998). Chan (1996: 109) also came up with "a new way of conceptualising police culture" by applying Bourdieu (1985)'s model of the interplay between field (i.e. structural dispositions) and habitus (i.e. cultural dispositions) to policing in Australia. She concludes that Bourdieu's theory "allows for the existence of multiple cultures since officers in different organisational positions operate under different sets of field and habitus" (Chan, 1996: 115). Both frameworks create opportunities for understanding variation in the attitude of police officers in different agencies towards the public. Chan (1996)'s framework has the additional advantage that it could be applied in research comparing the police with other occupations, because of its profession-neutral conceptualisation. However, in our opinion, Bourdieu's model needs further operationalization and elaboration of the overall hypotheses behind it. Arguably, GGCT would be a better alternative because it provides such operationalization and proposes a number of causal claims (see below).

\section{Grid-group cultural theory as an alternative framework}

\section{Two dimensions, four organisational forms}

This section aims to address the two criticisms on the traditional police culture model discussed above by presenting grid-group cultural theory (GGCT) as an alternative framework. GGCT was originally developed by Mary Douglas (1970) on the basis of her own ethnographic research, but later applied in different research domains (Mars, 1982; Thompson, Ellis, \& Wildavsky, 1990; Jensen, 1998; Hood, 1998; Vaughan, 2002; Maesschalck, 2004; Loyens, 2012 \& 2013). The framework provides a typology for a number of organisational forms, based on two dimensions: 'grid' and 'group'. 'Grid' refers to the extent to which an individual's life is bounded by externally imposed rules, prescriptions, and stratification. The more 'grid', the less of life is open to individual negotiation (Thompson et al., 1990). 'Group' stands for the incorporation of an individual into a bounded unit of actors or the extent to which individual choice is constrained by group choice (Hood, 1998). The greater the incorporation, the more of individuals' behaviour is constrained by the group. When these two dimensions are combined in a matrix, four organisational forms (i.e. job characteristics in this paper ${ }^{1}$ ) can be identified (see Table 1): hierarchy (high grid, high group), egalitarianism (low grid,

\footnotetext{
${ }^{1}$ Job characteristics in this paper refer to aspects like the frequent encounters with lawbreakers, and not to broader societal factors. The latter could, however, also have an impact on the occupational culture in the police and comparable professional groups. Although these aspects will not be discussed in this paper, GGCT might also capture such factors (e.g.
} 
high group), individualism (low grid, low group), and fatalism (high grid, low group). GGCT argues that these cultural types shape individuals' behavioural styles (i.e. attitudes towards the public in this paper) and that the four types should be combined in an organisation to avoid possible excesses that result from blind-spots of each separate type (Thompson et al., 1990). As will be explained below, too much emphasis on hierarchy could lead to rule-fetishism, too much egalitarianism to schism, too much individualism to anarchy and too much fatalism to desperation (Schwartz, 1991). By, however, combining or balancing organisational forms, such excesses are prevented and compensated for by the other types. The four cultural types will be briefly described below.

\section{-TABLE 1 ABOUT HERE-}

In hierarchy, rules prescribe roles and positions, while the group attachment provides legitimacy for the organisational stratification (O'Riordan \& Jordan, 1999). Hence, status is derived from one's position in a well-defined group. The central assumption is that each individual has his/her place and role with accompanying responsibilities. Individual interests are subjected to the collective good (Thompson et al., 1990) and conflicts can only be solved by applying legitimate rules. This organisational culture could, however, lead to rule-fetishism (Schwartz, 1991) when it is not combined with the other three types.

In egalitarianism, not formal rules and procedures are central, as in hierarchy, but deliberation in order to reach consensus (Rayner, 1986; Smullen, 2007). The group boundaries are clearly set, leading to an 'us-versus-them' attitude and distrust to outsiders, which can be illustrated with practices like scapegoating or 'blaming'. Within the group, solidarity is highly valued and individual interests are subjected to the welfare of the group or the higher good (Rayner, 1986). This type (when not combined with the other types) could, however, lead to deficient decision making and disruption in the group because consensus is not always feasible or could lead to excesses (Jensen, 1998).

Individualism is a cultural type characterized by competition (Rayner, 1986). An individualistic culture stimulates the strive for self-interest (Verweij et al., 2006) in which opportunistic networks are developed where tit-for-that strategies are used to make deals that are profitable for both actors. Conflicts are dealt with by bargaining practices and one-on-one negotiation. Undiluted individualism could, however, lead to anarchy (Schwartz, 1991).

Fatalism is often considered a passive way of life, distinguished from the three active types. Central in this cultural type is that individuals are (or feel) bound by a system of rules that is beyond their control, and against which they cannot undertake collective action, due to a lack of group affiliations (Vaughan, 2002). Other human beings are looked at with suspicion, because one never knows what to expect from them (Thompson et al., 1990). The fatalistic world is considered a lottery, characterized by unpredictability and chance, possibly leading to desperation (Schwartz, 1991). Hence, trying to survive is the main coping strategy (O'Riordan et al., 1999). Despite its negative

political reforms, economic crises, demographic evolutions), as it can be applied at all levels of social scale and all domains of human life (Verweij et al. 2006). 
connotation, fatalism can be a valuable perspective, because it can release individuals from excessive burdens of responsibility by introducing some form of acquiescence and scepticism.

\section{Reconceptualising the attitude towards the public on the basis of GGCT}

This section illustrates how GGCT can be used to reconceptualise the way in which the traditional police culture model has presented police-public interactions. First, it shows how the classic conceptualisation fits into GGCT. Second, it illustrates how GGCT can broaden the lens by identifying other ways in which the interaction with the public could be conceptualised. Arguably, GGCT opens a window for conducting comparative research on the attitude of various professional groups towards citizens.

Egalitarianism and fatalism are most prominent in the way in which the classic police culture model presents police-public interactions. Egalitarianism is closely related to the frequent encounters with lawbreakers, which is a central characteristic of the police job according to the police culture literature (see above). Because police officers are often confronted with "the worst side of humanity" (Goldstein, 1975: 25), their aversion against criminals is relatively high, this literature argues. This could lead to a strong demarcation line between themselves and society, or in other words an 'usversus-them' attitude. At the same time, there is a moral mission to protect society as being the 'good guys' in the struggle between good and evil (Chan, 1996). A constable in Reiner (1978: 247)'s study even calls his police department "a sect [...] a religion". This can also be related to the egalitarian subculture - that is sometimes referred to as a sect (Rayner, 1982) - where insiders consider themselves the pure ones who have to fight the bad ones out of a sense of righteousness. Because egalitarian subcultures blame the system when rules are unfair or ineffective, violating them to achieve a higher goal is sometimes necessary (e.g. noble cause corruption).

Various fatalistic aspects can also be found in the classic police culture model. This can be illustrated by police officers' feeling of powerlessness towards criminals or 'bad guys' who manage to get away with breaking the law as a result of legal loopholes. Police officers feel restrained by rules and procedures (high grid) that remain ineffective to catch criminals. Fatalism is also manifested in the insecurity and unpredictability that characterizes the police job (see above). This leads to suspicion towards the public, possibly even paralyzing individual officers. The concept of 'moral cynicism' in the police culture literature can be linked to fatalism as well. Although this attitude seems to contradict their strong sense of mission and emphasis on the higher purpose, which is an egalitarian aspect, Reiner (1992) states that cynicism is the flip-side of commitment that can even help to reinstate their sense of mission. In other words, and as mentioned above, fatalism helps individuals to put things in perspective by introducing some form of acquiescence.

GGCT opens opportunities to look at other ways in which the police (or comparable professional groups) could interact with the public. By broadening the analytic lens, this theory allows for the identification of cultural aspects within the police that the traditional literature tends to overlook. The interaction with the public could, for example, also have hierarchical or individualistic aspects. As for the interaction with suspects, hierarchy would imply treating them as subordinates "who should first and foremost be pressed to comply with the law" (Loyens, 2012: 56). Police officers then treat 
suspects as they should be treated according to the rules. Hierarchy also implies the importance of procedural justice (Tyler, 1988) or fairness, in the sense that the rules should be changed if applying them would lead to unfair treatment of citizens. As for the interaction with the wider public or victims of crimes, hierarchy is characterized by paternalism. Police officers then consider it part of their role and their responsibility to protect victims in ways that are prescribed in the legislation and official procedures.

Individualistic interaction with suspects is characterized by reciprocity and a give-and-take attitude. This would mean that police officers make deals with suspects so both parties benefit, e.g. "I will turn a blind eye to this, if you will confess that". This resembles the 'tit-for-that' enforcement strategies that Maesschalck (2004: 19-20) refers to in his empirical study of social and environmental inspectors, in which inspectors "apply the regulations flexibly", especially in the case of first-time violations, "but only as long as the inspectee acts cooperatively". Central in this individualistic perspective is that police officers are mainly interested in achieving personal results and benefits, rather than following procedures and abiding by hierarchical principles, such as equal treatment. Individualistic interaction with victims is also characterized by reciprocity, in the sense that a police officer only helps those victims who give something in return that is beneficial for him or her. A case in point is a victim who gives a police officer important information to do a successful investigation.

\section{Applying the new conceptual framework in a Belgian case study}

\section{Methodology}

This newly developed conceptual framework has been tested in an ethnographic study (Hammersley \& Atkinson, 1995) in the Belgian police and labour inspection. ${ }^{2}$ Over 670 hours of observations, informal conversations and in-depth interviews were conducted over a period of 21 months. The data were collected in two investigative teams of the Belgian federal police that deal with human trafficking and human exploitation crimes and two field organizations of the Inspection of Social Laws in Belgium that enforces labour laws and performs regular inspections on illegal work and unregistered work. ${ }^{3}$ The investigative teams and field organizations consisted of 8 to 15 respondents. Most of them were interviewed ${ }^{4}$ ( 43 respondents in total among whom 32 front-line officers and 11 supervisors) and all of them were observed in different situations (e.g. inspections, house searches, meetings, interrogations, etc.). The group of respondents was sufficiently varied in terms of age ${ }^{5}$, $\operatorname{sex}^{6}$ and education level ${ }^{7}$. During the in-depth interviews and informal conversations, the respondents were invited to describe and explain their attitude towards citizens (i.e. victims and

\footnotetext{
${ }^{2}$ The results in this paper are part of a broader qualitative study (Loyens, 2012), which aimed at explaining how organisational factors impact the way in which detectives and labour inspectors deal with moral dilemmas. The goal of this study was not generalization to a wider population, but theory-building by developing hypotheses that could be tested in future research (Smaling, 2003).

${ }^{3}$ To protect the respondents' identity, the region in which the organizations are located will not be mentioned. Moreover, their sex will be concealed by randomly using 'he' or 'she'.

${ }^{4} 2$ persons declined participation in the interviews and 3 persons cancelled the interview appointment for private reasons. However, the researcher had various informal conversations with all these individuals during the data collection period.

${ }^{5}$ Ranging from 25 to 60 years old, with an average of 45.

${ }^{6} 30$ male respondents and 13 female respondents.

${ }^{7} 15$ respondents with a Master's degree, 15 with a Bachelor's degree and 13 with a high school degree.
} 
suspects). ${ }^{8}$ The interviews were recorded and transcribed verbatim and the informal conversations were summarized in detailed reports. Observations of encounters with the public (that complemented the narratives) were summarized in field reports. This resulted in rich data and 'thick description' (Geertz, 1973). The data were analysed with the qualitative software Nvivo using topic coding and analytic coding (Richards \& Morse, 2007).

\section{Results}

This section illustrates the attitude of police officers and labour inspectors in this study towards the public, operationalized in GGCT. It focuses on the interaction with suspects and the interaction with victims. ${ }^{9}$

\section{Attitudes towards suspects}

The attitude towards suspects was, in all four research settings, partly characterized by hierarchy. The respondents considered it important to maintain a neutral attitude and keep professional distance towards potential perpetrators. This can, in the police, be illustrated by the statement of a detective that one should always look for any and all evidence, not only in disfavour but also in favour of the suspect. Hierarchy in the labour inspection settings presented itself as taking the middle position between the employer and the employee, because they both tell a partial truth. Such neutrality was particularly difficult for staff members who had previously worked in a labour union where the employer is to a certain extent considered 'the enemy'. It was equally difficult for staff members with a social work background who were often prone to protect the weaker party (i.e. the employee). The latter type of attitude can be described as an egalitarian sense of moral mission (an important issue in the police culture literature: see above), which can thus sometimes conflict with hierarchical neutrality.

The interaction between respondents in this study and suspects, however, also showed individualistic aspects, which became clear in negotiation practices. A case in point in the police settings is the implicit negotiation tactic in house searches without a warrant. When a suspect did not give detectives permission to enter his house, the latter sometimes explicitly stated that the suspect had the right to do so, but added that it was probably not in his best interest because it made him appear suspicious. Although this conflicts with hierarchical principles (e.g. respect for the suspect's right to refuse a house search), negotiation is sometimes alluring because it might lead to quick results in an investigation.

Negotiation in the labour inspections occurred both in an explicit and an implicit manner, but was mostly aimed at achieving a win-win situation for inspectors and employers who had violated labour laws. In explicit negotiation, labour inspectors in both research settings sometimes made employers the offer to drop charges for unregistered work violations (which is against internal guidelines) if the

\footnotetext{
${ }^{8}$ To diminish socially desirable behaviour and speech (an important risk in empirical research, see Bailey 1994), two types of triangulation were used: (1) within-methods triangulation by combining data collection methods to validate each other and (2) data source triangulation by looking for variation in situations, places, events and persons that are studied to increase reliability (Denzin 1978).

${ }^{9}$ As for the labour inspection, suspects are mostly employers who violate labour laws and victims are mostly employees who are deprived of certain rights by their employer (e.g. insufficient wage).
} 
employers would rectify other labour law violations (e.g. payment of deprived wages). ${ }^{10}$ Those inspectors added that they were not sure whether or not they were legally allowed to overlook such serious violations. However, they did so anyway, because labour inspectors have to meet certain targets for rectification amounts, which encourages explicit negotiation practices. Negotiation was often also done in an implicit way. This can be illustrated with a quote of an inspector:

Well, there are people who think 'there is one of those labour inspectors again, let's give him a hard time', and then I think to myself: 'Man, I have much more possibilities to give you a hard time', but that is not my initial attitude. [...] I try to give people a taste of their own medicine. When they are friendly and cordial, then I am too.

Different inspectors in both settings explained that when employers show their 'goodwill', they do not 'nit-pick' by looking for minor violations. If, on the other hand, an employer was known for never complying with the rules, he would get a report for everything (even very small violations), which is against internal guidelines that suggest labour inspectors should not make a report for minor violations (e.g. absence of a labour regulation code). As was the case in the police, such practices in the labour inspections can conflict with the aforementioned hierarchical principals of neutrality and equal treatment.

In the four settings, evidence was found for an egalitarian attitude towards suspects as well, which was mostly expressed by an 'us-versus-them' attitude towards suspects. Police officers and labour inspectors often made a stereotypical distinction between real criminals and people who just made a mistake. They often did so on the basis of a few subjective indicators, such as perceived trustworthiness. If a suspect was at first sight labelled as untrustworthy, he was often stereotyped as a 'real criminal', and then most respondents did not show him mercy or respect. This can be illustrated by respondents' remarks like: "I know these men [...] They are scum [...] I would really like to knock them over with my car" and "We get the dirt of the street". However, seemingly trustworthy suspects were often considered people who just made a mistake and who deserve lenience. Such stereotyping - that goes against hierarchical principles of neutrality and equal treatment (see above) - might lead to preferential treatment of those one trusts above those one does not trust.

Finally, respondents in all four settings regularly showed a fatalistic attitude towards perpetrators, mainly because they felt powerless to 'catch' them. This was sometimes coped with by some form of acquiescence, as illustrated in the following quote of an inspector: "Well, it's what they say, all we do is move paper around, so you catch someone and then you send the report to the public prosecutor and he sends it to an administrative agency and the perpetrator can just continue committing fraud". Respondents in all four settings explained that perpetrators have ample opportunity to circumvent legislation and not get caught. Detectives, for example, explained that suspects nowadays know how they can organize sexual exploitation without risking prosecution (e.g. preventing that victims feel

\footnotetext{
${ }^{10}$ Labour inspectors in Belgium have the discretion to (1) give a warning, (2) make a report, (3) or offer the employer the option to rectify the violation within a set term. The head office issues internal guidelines to encourage equal application of this discretion.
} 
victimized by letting them keep half of the money they earn). A detective stated: "I think everything evolves, our tactics evolve, but I guess that also counts for the modi operandi of the people we go after, because they learn from the verdicts. They would be stupid if they didn't."

In the inspection settings, respondents also complained about employers being able to exploit legal loopholes. They, for example, explained how employers in the catering industry circumvent the rules by letting employees use two types of cards for time registration so they can employ them full-time but only register them part-time, and hence evade taxes. Another strategy that was mentioned is stalling inspectors at the door to give illegal workers the opportunity to flee, while the employer only risks a report for hindrance of inspection, which is (according to inspectors) almost never prosecuted. Inspectors in both settings also felt powerless against the real fraudsters who managed to lead their firm into bankruptcy and start a new firm with a straw man - leaving labour inspectors with the impression that they can only catch the 'small fish'.

\section{Attitudes towards victims}

Towards victims, labour inspectors' attitudes were (at least partly) characterized by hierarchy in the sense that respondents considered themselves to be neutral actors between employers who commit labour law violations and their victimized employees. Victims were treated in ways prescribed in the legislation that emphasizes a paternalistic attitude and neutrality. However, in the most serious investigations some inspectors put this neutral attitude aside and sympathized with employees, considering them a partner in a joint fight against exploitative employers, which is an egalitarian attitude. In both inspections, the respondents claimed that they got more satisfaction out of demanding employers to rectify certain labour law violations than out of giving them a fine. The former would, in their opinion, lead to helping exploited employees, while the latter would only be beneficial for the treasury. One inspector stated that she was used to helping employees in her previous job in the labour union, and, therefore, she sometimes gets carried away and tries to help them more than she ought to do as a neutral labour inspector. While we observed a significant number of examples of an egalitarian attitude, in the interviews many inspectors claimed to always take a neutral (and thus hierarchical) position between employers and employees. This hierarchical claim seemed, at least in some cases, to be a means to remind (and perhaps even convince) not only the interviewer but also themselves of their neutrality, which is not always kept in practice.

In the interaction between labour inspectors and illegal employees, an hierarchical attitude is also important in labour inspectors' opinion. Several respondents explained that they often feel compassionate towards illegal employees, because they do not have another option but than to work in an illegal way in order to survive. They would sometimes prefer to turn a blind eye for illegal work to protect these illegal employees (which would be an egalitarian response). However, they mostly take their responsibility by turning them over to the police, which is the official procedure and thus the result of an hierarchical attitude. An inspector said: "No I mean, I try, in these cases, to act like a robot, because if you act like a human being you never call the police again. [...] Then you have to turn your heart into a rock. You have no other options." Although most inspectors generally did their duty by calling the police when confronted with illegal employment, some refused because the egalitarian sympathy towards illegal workers was stronger. 
In the police settings, the egalitarian sense of mission to save exploitation victims was particularly strong. This can be illustrated by cases in which detectives wanted to continue the investigation, even when the public prosecutor had already instructed them to stop the investigation. The hierarchical response would be to follow the public prosecutor's decision, but their egalitarian sense of mission encouraged them to continue the investigation.

The interaction with victims was in all four settings also partly characterized by fatalism. This was manifested in a twofold way. First, respondents complained about victims or exploited employees not wanting to be 'saved'. Victims of exploitation were, according to police detectives, sometimes not willing to file a complaint against perpetrators, sometimes out of fear, but mostly because they did not consider themselves real victims. In such cases, police officers felt powerless, because they needed the victims' statement in order to take action against perpetrators. Labour inspectors sometimes also felt powerless to help employees, for example, when they refused to give a statement. Sometimes, employees were too afraid to give a statement, because they did not want to risk losing their job, even if moonlighting led to not being able to benefit from certain social rights (e.g. protection against unemployment and sickness). Second, respondents in the four settings stated that victims or employees sometimes abused the system. Detectives referred to situations in which the line between victim and perpetrator was not clear-cut. A case in point was a prostitute who filed a complaint for having been brutalized, while in fact she started beating the pimp first because she was under the influence of illegal drugs. Another example is a prostitute who made up a story of abuse by a particular pimp so she could start working for another one. The respondents in the labour inspection also referred to risks of abuse, for example by employees who file false complaints as part of family quarrels or divorce proceedings.

\section{Conclusion}

This paper illustrated how GGCT could be used as an alternative conceptual framework to study certain aspects of police occupational culture. The argument was made that GGCT addresses the two criticisms against the classic police culture literature mentioned above. First, it offers more neutral concepts and thus helps avoiding the pejorative connotations of the traditional police culture model. Second, GGCT allows for comparative research between different professional groups because it is profession-neutral. Despite these advantages, the application of GGCT creates new potential risks. First, models with broad ambitions run the risk of generating gratuitous, sweeping generalisations that have no real connection with empirical reality. We argue that this problem can be avoided by applying the operationalization of the general categories to specific domains, as was done in the empirical study described above. Second, there is the risk of theoretical rigidity by manipulating or forcing empirical data to fit the framework (i.e. the four GGCT types) (Lofland et al., 2006). This risk could be reduced by constantly keeping an open mind to data that do not seem to fit the framework. This relates to the third risk, the falsifiability of GGCT. The theory has regularly been criticized for not being falsifiable. Thompson and colleagues (1990), however, argue that GGCT can be falsified if empirical studies find that a specific organizational form does not lead to the corresponding behavioural style. This would, for example, be the case when a combination of hierarchical and 
egalitarian job characteristics in certain police agencies would mainly generate hierarchical attitudes towards the public or if hierarchical job characteristic would lead to both hierarchical and egalitarian attitude towards the public. In the doctoral study that was the basis of this paper (Loyens, 2012), looking for falsification of GGCT was an explicit aim, but the theory was nevertheless confirmed. Although GGCT has gained sufficient plausibility, being applied in various empirical studies in different domains, future research should however remain critical and look for ways to falsify the theory to test its applicability in particular organisations.

Despite the aforementioned risks, this study showed that GGCT is promising as an analytic framework to study aspects of police occupational culture and compare them with the occupational culture in other professional groups. Similarities could be observed in the way in which Belgian police officers and labour inspectors interact with the public, which raises interesting questions concerning the (often implicit) claim of the police culture literature concerning the specificity of police culture. However, the results of this study cannot be generalized to police organizations or labour inspections in general, neither in Belgium nor abroad, which is mainly due to the qualitative in-depth approach and the relatively small sample size. The aim of the study was exploratory and to develop theory, not to generate claims applicable to a whole population. Hence, more research is needed to gain insight in similarities of and differences between the occupational culture in the police and comparable professional groups. This paper argued that GGCT offers a useful conceptual framework for such a research agenda and by doing so broadens the lens of the classic police culture literature. 


\section{REFERENCES}

Ames, W. (1981) Police and community in Japan. Berkeley: University of California Press.

Bailey, K. D. (1994). Methods of social research. New York: Free Press.

Bayley, D. H. (1991) Forces of order: Police behaviour in Japan and the United States (2nd ed.). Berkeley: University of California Press.

Bourdieu, P. (1985) The genesis of the concepts of habitus and field. Sociocriticism 2 (1): 1-24.

Brogden, M. \& Shearing, C. D. (1993) Policing for a new South Africa. London: Routledge.

Brown, M. K. (1981) Working the street: police discretion and the dilemmas of reform. New York: Russell Sage Foundation.

Chan, J. (1996) Changing police culture. British Journal of Criminology 36 (1): 109-134.

Crank, J. P. (1997) Celebrating agency culture: engaging a traditional cop's heart in organizational change. In Q. C. Thurman \& E. F. McGarrell (Eds.) Community policing in a rural setting. Cincinnati: Anderson Publishing, 49-57.

Crank, J. P. (1998) Understanding police culture. Cincinnati OH: Anderson Publishing.

Denzin, N. K. (1978). The research act: A theoretical introduction to sociological methods. New York: McGraw-Hill.

Douglas, M. (1970) Natural symbols: explorations in cosmology. New York: Random House.

Goldstein, H. (1975) Police corruption: A perspective on its nature and control. Washington DC: Police Foundation.

Hammersley, M. \& Atkinson, P. (1995) Ethnography. Principles in practice. London: Routledge.

Harrison, S. J. (1998) Police organizational culture: using ingrained values to build positive organizational improvement. Public Administration and Management: An Interactive Journal 3 (2).

Herbert, S. (1998) Police culture reconsidered. Criminology 36 (2): 343-369.

Hood, C. (1998) The art of the state. Culture, rhetoric, and public management. Oxford: Clarendon Press.

Jensen, L. (1998) Cultural theory and democratizing functional domains. The case of Danish housing. Public administration 76 (1): 117-139.

Jiao, A. Y. (2001) Police and culture: a comparison between China and the United States. Police Quarterly 4 (2): 156-185.

Loftus, B. (2009) Police culture in a changing world. Oxford: Oxford University Press.

Loyens, K. (2012) Integrity secured. Understanding ethical decision making among street-level bureaucrats in the Belgian Labor Inspection and Federal Police. KU Leuven, Leuven. 
Loyens, K. (2013). Why police officers and labour inspectors (do not) blow the whistle: A grid group cultural theory perspective. Policing: an international journal of police strategies \& management 36 (1), 27-50.

Maesschalck, J. (2004) Towards a public administration theory on public servant's ethics. Katholieke Universiteit Leuven, Leuven.

Manning, P. K. (1995) The police occupational culture in Anglo-American societies. In W. Bailey (Ed.) The encyclopedia of police science. New York: Garland Publishing, 472-475.

Mars, G. (1982) Cheats at work. An anthropology of workplace crime. Aldershot: Ashgate.

Mastrofski, S. D., Worden, R. E., \& Snipes, J. B. (1995) Law enforcement in a time of community policing. Criminology 33 (4): 539-563.

McLaughlin, E. (2007) The new policing. London: Sage.

Monjardet, D. (1994) La culture professionnelle des policiers. Revue française de sociologie 35 (3): 393-411.

O'Riordan, T. \& Jordan, A. (1999) Institutions, climate change and cultural theory: Towards a common analytical framework. Global Environmental Change 9 (2): 81-93.

Paoline, E. A. I. (2003) Taking stock: toward a richer understanding of police culture. Journal of Criminal Justice 31 (3): 199-214.

Prenzler, T. (1997) Is there a police culture? Australian Journal of Public Administration 56 (4): 47-57.

Punch, M. (1979) Policing the inner city: a study of Amsterdam's Warmoesstraat. Hamden: Archon books.

Rayner, S. (1982) The perception of time and space in egalitarian sects: a millenarian cosmology. In M. Douglas (Ed.) Essays in the sociology of perception. London: Routledge \& Kegan Paul, 247274.

Rayner, S. (1986) Management of radiation hazards in hospitals: Plural rationalities in a single institution. Social Studies of Science 16 (4): 573-591.

Reiner, R. (1978) Blue-coated worker: A sociological study of police unionism. New York: Cambridge University Press.

Reiner, R. (1992) The politics of the police. New York: St. Martins' Press.

Reuss-lanni, E. (1983) Two cultures of policing: street cops and management cops. New Brunswick and London: New Brunswick Transaction.

Richards, L. \& Morse, J. M. (2007) Readme first for a user's guide to qualitative methods. Thousand Oaks (CA): Sage.

Schwartz, B. (1991) A pluralistic model of culture. Contemporary Sociology 20 (5): 764-766.

Skolnick, J. H. (1975) Justice without trial: law enforcement in democratic society. New York: John Wiley and Sons. 
Smaling, A. (2003) Inductive, analogical, and communicative generalization. International Journal of Qualitative Methods 2 (1): 52-67.

Smullen, A. J. (2007) Translating agency reform. Rhetoric and culture in comparative perspective. Erasmus Universiteit Rotterdam, Rotterdam.

Swidler, A. (1986) Culture in action: Symbols and strategies. American Sociological Review 51 (2): 273-286.

Terrill, W., Paoline, E. A. I., \& Manning, P. K. (2003) Police culture and coercion. Criminology 41 (4): 1003-1034.

Thompson, M., Ellis, R., \& Wildavsky, A. (1990) Cultural Theory. Boulder: Westview Press.

Tyler, T. R. (1988) What is procedural justice? Criteria used by citizens to assess the fairness of legal procedures. Law \& Society Review 22 (1): 103-136.

van Buuren, J. \& den Boer, M. (2008). State-of-the-art literature review on the ethics research and knowledge among security professionals. Security ethics: a thin blue line. Inex.

Van Maanen, J. (1974) Working the street: A developmental view of police behaviour. In H. Jacob (Ed.) The potential for reform of criminal justice. Beverly Hills: Sage, 83-130.

Vaughan, B. (2002) Cultured punishments: the promise of grid-group theory. Theoretical Criminology $6(4): 411-431$.

Verweij, M., Douglas, M., Ellis, R., Engel, C., Hendriks, F., Lohmann, S. et al. (2006) Clumsy solutions for a complex world: The case of climate change. Public administration 84 (4): 817-843.

Westley, W. A. (1970) Violence and the police: A sociological study of law, custom, and morality. Cambridge: MIT Press. 
Table 1: Two dimensions and four types in GGCT

\begin{tabular}{|c|c|c|}
\hline & Low group & High group \\
\hline High grid & $\begin{array}{l}\text { FATALISM } \\
\text { Central idea: Individuals are bounded by a } \\
\text { system of rules that is beyond their control. } \\
\text { Conflicts can be dealt with if you are lucky; } \\
\text { just try to survive. } \\
\text { Risk of inertia and the unwillingness to plan } \\
\text { ahead or take necessary measures. }\end{array}$ & $\begin{array}{l}\text { HIERARCHY } \\
\text { Central idea: Rules prescribe roles and } \\
\text { responsibilities within a well-defined group. } \\
\text { Conflicts can be dealt with by referring to } \\
\text { rules and authority. } \\
\text { Risk of misplaced trust in procedural rules } \\
\text { and authority. }\end{array}$ \\
\hline Low grid & $\begin{array}{l}\text { INDIVIDUALISM } \\
\text { Central idea: Individuals are entrepreneurs } \\
\text { that operate in a competitive environment. } \\
\text { Conflicts can be dealt with by one-on-one } \\
\text { negotiation and bargaining. } \\
\text { Risk of chaos due to a lack of cooperation } \\
\text { and tendency to put the individual above the } \\
\text { common good. }\end{array}$ & $\begin{array}{l}\text { EGALITARIANISM } \\
\text { Central idea: Everyone is equal and should } \\
\text { cooperate for the welfare of the group. } \\
\text { Conflicts can be dealt with by group } \\
\text { negotiation in order to reach consensus. } \\
\text { Risk of inefficient decision making and even } \\
\text { disruption of the group by scapegoating or } \\
\text { removing the bad apple. }\end{array}$ \\
\hline
\end{tabular}

